\title{
JOURNAL.RU
}

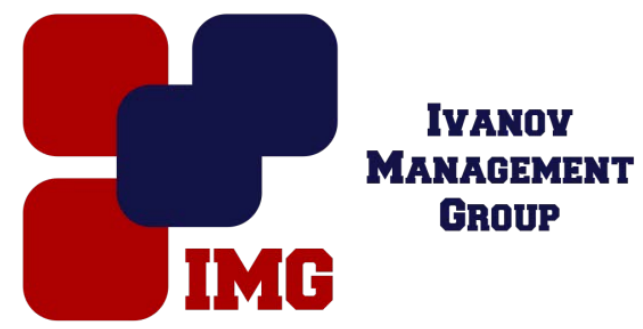

Дерябина А.А. Национальный Исследовательский Томский Государственный университет

Томск, Россия

doi: 10.18411/lj-31-01-2017-4-04

idsp 000001:lj-31-01-2017-4-04

\section{Радиационный контроль на сибирском химическом комбинате с целью обеспечения экологической безопасности}

\section{Аннотация}

Объектом данного исследования является автоматизированная система радиационного контроля Сибирского химического комбината.

Основным видом деятельности СХК является производство ядерного топлива для российских и зарубежных атомных станций. В процессе деятельности СХК осуществляет выбросы радиоактивных веществ в атмосферный воздух. Актуальность выбранной темы определяется необходимостью безопасного производства продукции мирового качества на базе современных технологий при обеспечении безопасности населения, проживающего в районе расположения СХК. В статье рассмотрена система функционирования АСКРО - СХК и возможности обновленной системы, работы по модернизации которой происходят в настоящее время.

Ключевые слова: радиационная безопасность, автоматизированная система контроля радиационной обстановки, Сибирский химический комбинат, модернизация, Госкорпорация «Росатом»

Решить задачу радиационной безопасности возможно при осуществлении соответствующего радиационного контроля, позволяющего получать необходимые данные о состоянии окружающей среды и степени воздействия эксплуатируемых на СХК заводов основного производства. Составной частью системы производственного радиационного контроля окружающей среды, действующей на СХК, является контроль мощности дозы гамма-излучения на местности. Для реализации данного вида контроля на СХК создана и успешно эксплуатируется автоматизированная система контроля радиационной обстановки - АСКРО - СХК.

АСКРО - СХК введена в постоянную промышленную эксплуатацию на СХК в 2000 году. На тот момент в состав системы входили 2 поста 
радиационного контроля, расположенные в городе Северске, на базе приборов КСП-4 и УИМ2-2. Система совершенствовалась, количество постов увеличивалось и на сегодняшний момент их число достигло 10.

Посты контроля мощности дозы гамма-излучения находятся в г. Томске (район АРЗА), п. Самусь, д. Наумовка, д. Копылово, в которых эксплуатируются по одному посту, в г. Северске (три поста - "Детская больница", "Профилакторий", "АИК"). Кроме того посты располагаются на территории, где расположены заводы СХК.

Ближайший от завода СХК пост контроля находится на расстоянии $~ 600$ м. Поэтому повышенный выброс радиоактивных веществ из трубы завода в атмосферу в считанные минуты будет зарегистрирован на посту и информация об этом поступит на рабочее место начальника смены комбината, где расположен центральный пункт сбора данных.

Для контроля сточных вод, поступающих в реку Томь, в составе АСКРО СХК используется только один пост "ВХ-1", поскольку сбросной канал, где установлен радиационный контроль АСКРО, является единственным сбросным каналом, в воде которого могут содержаться радиоактивные вещества.

Имеется пост контроля фоновой мощности экспозиционной дозы гаммаизлучения в д. Победа. Поскольку этот пост расположен в населенном пункте с наветренной стороны и на расстоянии более 50 км к юго-западу от Сибирского химического комбината, заводы комбината не могут влиять на уровни мощности дозы гамма-излучения, регистрируемые на этом посту.

Измерение мощности дозы гамма-излучения осуществляется на постах контроля при помощи датчика БДМГ-08 в диапазоне от 1 до 1000 мкР/час, сигнал с которого поступает на блок функциональной обработки БПМ-54.

Метеостанция позволяет вести непрерывный контроль направления ветра, относительной влажности, атмосферного давления, температуры окружающей среды в диапазоне от минус $40^{\circ} \mathrm{C}$ до плюс $50^{\circ} \mathrm{C}$, скорости ветра в диапазоне от 2 до $30 \mathrm{M} / \mathrm{c}$.

Измерение метеопараметров производится с использованием ультразвуковой станции «МЕТЕО-2», в состав которой входят измерительная ультразвуковая головка и блок датчиков влажности и давления.

Система АСКРО может функционировать в трех режимах:

- в режиме повседневной деятельности (штатный режим при уровнях до 60 мкР/час);

- в режиме повышенной готовности (предаварийный режим при уровнях от 60 до 120 мкР/час);

- в аварийном режиме (при уровнях МЭД, превышающих 120 мкР/час).

Периодичность опроса постов контроля мощности дозы гамма-излучения (задается оператором в зависимости от требуемого режима) может составлять от 10 до 60 минут, поста контроля метеопараметров - или непрерывно (по прямому 
кабельному соединению), или периодически через 30 минут (с использованием телефонной линии связи).

При обнаружении системой АСКРО превышений установленных пределов мощности дозы гамма-излучения на экране монитора появляется цветовое отображение информации и выдается звуковое сообщение о превышении.

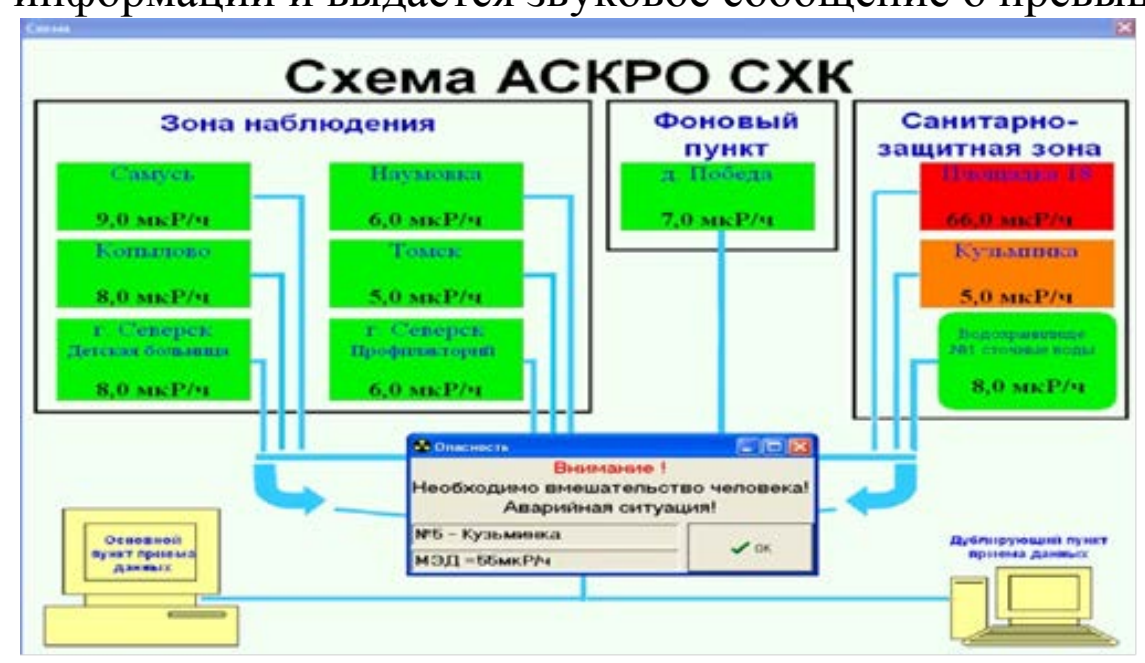

Рисунок 1 - Пример визуального представления на экране монитора компьютера данньх контроля при превымении «допустимого» и «аварийного» уровней мощзности дозы гаммаизлучения.

Со временем действующая система АСКРО устарела, для ее обновления Госкорпорация «Росатом» выделила средства и в настоящее время ведутся работы по ее модернизации.

Новая система АСКРО АО “СХК” обеспечит реализацию дополнительных возможностей:

1. Проводить измерения мощности дозы гамма-излучения в единицах измерений системы СИ (зиверт) взамен внесистемных единиц измерений (рентген).

2. Вместо мощности экспозиционной дозы будет измеряться мощность амбиентного эквивалента дозы, что позволит использовать результаты измерения без перехода от одной величины к другой.

3. Появится возможность измерять не только мощность гаммаизлучения, но и проводить спектрометрический анализ воздушной и водной среды (нуклидный состав: (Цезий-137, Церий- 144, Рутений-106).

4. Измерение мощности дозы будет осуществляться в воде, а не над водой.

5. Автоматизированная передача данных гамма-съемки на местности, определение координат и нанесение на карту мест измерений.

6. Монтаж жидкокристаллических табло позволит визуализировать получаемые системой АСКРО АО «СХК» данные на современном уровне. 
По наблюдениям автора, действующая система АСКРО - СХК выполняет возложенные на нее функции, но устаревшие средства измерения, связи и передачи данных системы выработали свой ресурс (годы выпуска 1992 - 2001) и сняты с производства, что делает не возможной замену выходящих из строя частей системЫ. Модернизация системы АСКРО АО “СХК” позволит решить проблему замены и ремонта приборов, выходящих из строя. В обновленной системе появится возможность спектрометрического анализа воздушной и водной среды, что позволит оперативно получать информацию о содержании определенных радионуклидов в окружающей среде.

\section{Литература}

1. Рабочая инструкция «О порядке эксплуатации автоматизированной системы контроля радиационной обстановки акционерного общества «Сибирский химический комбинат»»»

2. Руководство по эксплуатации «Комплекс автоматизированной утразвуковой метеорологический «Метео-2» КНША 098.100РЭ

3. Краткое описание «Программный комплекс «Мониторинг»»

4. Техническое задание на поставку стандартного промышленного оборудования для объекта (автоматизированная система контроля радиационной обстановки $\mathrm{AO}$ «СХК» (АСКРО СХК) 